\title{
AS EXPRESSÕES ARTÍSTICAS DISPOSTAS NOS MUROS DAS ESCOLAS: Significados e Desvelamentos Sobre a Relação Cidade-Escola
}

\author{
Danielle De Marchi Tozatti ${ }^{1}$ \\ Sandra Regina Ferreira de Oliveira ${ }^{2}$ \\ Eliane Aparecida Candotti ${ }^{3}$
}

\begin{abstract}
RESUMO
Este artigo reflete sobre o muro que cerca as escolas como espaço de socialização, revelador e instigador acerca do ambiente escolar. Aborda-se a temática grafite e pinturas encontrados nos muros de uma escola pública na cidade de Londrina (PR), na qual se questionam os caminhos percorridos na efetivação dessa arte, como e quais foram os sujeitos envolvidos e quais são as reverberações dentro do espaço escolar e no bairro. Trata-se de uma pesquisa exploratória descritiva, situada entre os campos dos estudos da cidade e os estudos da instituição escola, ambos interdisciplinares, além de registro fotográfico. Para a revisão bibliográfica foram sintetizadas as temáticas da linguagem, expressada por meio da arte urbana, e da cidade, formadora do conteúdo para a escola. Uma cidade e a educação escolar podem ser compreendidas por meio das representações dispostas nos muros das escolas, resultando em experiência, interesse e desenvolvimento dos alunos mediante a participação e o reconhecimento desse tipo de arte considerada urbana, além de proporcionar à escola motivações e criar um ambiente acolhedor para todos que a compõem.
\end{abstract}

Palavras-chave: Ambiente escolar. Arte urbana. Cidade-escola. Grafite.

ARTISTIC EXPRESSIONS ARRANGED ON SCHOOL WALLS: MEANINGS AND UNVEILING OF THE CITY-SCHOOL RELATIONSHIP

\begin{abstract}
This article reflects on the wall, which surrounds schools as a space for socialization, revealing and instigating the school environment. The thematic graffiti and paintings found on the walls of a public school in the city of Londrina (PR) are approached, in which we question the paths taken in the realization of this art, how and what were the subjects involved and what are the reverberations within the school space and on the neighborhood. This is a descriptive exploratory research, located between the fields of city studies and studies of the school institution, both interdisciplinary, in addition to photographic record. For bibliographic review, the themes of language expressed through urban art and the city that formed the content for the school were synthesized. A city and school education can be understood through representations placed on school walls, resulting in experience, interest and development of students through participation and recognition of this type of art considered urban, in addition to providing the school with motivations and creating a welcoming environment for all who compose it. Keywords: School environment. Urban art. School city. Graphite.
\end{abstract}

RECEBIDO EM: 20/1/2020

ACEITO EM: 24/3/2020

\footnotetext{
1 Autora correspondente. Universidade Estadual de Londrina. Rodovia Celso Garcia Cid, PR-445, Km 380 - Campus Universitário. CEP 86057970. Londrina/PR, Brasil. http://lattes.cnpq.br/0488173633806982. https://orcid.org/0000-0003-4584-7697 daniellemarchi@yahoo.com.br 2 Universidade Estadual de Londrina. Londrina/PR, Brasil. http://lattes.cnpq.br/9304053885604944. https://orcid.org/0000-0002-9777-4461. 3 Universidade Estadual de Londrina. Londrina/PR, Brasil. https://lattes.cnpq.br/8512090891203402. https://orcid.org/0000-0002-1827-6510.
} 
Muros são edificados para separar e proteger de um inimigo cujo perfil se altera a depender do tempo e do lugar. As muralhas que contornavam as cidades medievais, a Grande Muralha da China e o Muro de Berlim, são sínteses históricas que, cada qual a seu tempo, desvelam desenhos sociais que possibilitam compreender o desejo de proteção, de apartamentos e, concomitantemente, de agrupamentos. O muro define o espaço, dialoga com o entorno e provoca possibilidades de pensá-lo sob várias perspectivas: de dentro, de fora, de cima; excludente, agregador. De uma forma ou de outra, concorda-se com Frederico Garcia Lorca (2015), quando escreve que “[...] há coisas encerradas dentro dos muros que, se saíssem de repente para a rua e gritassem, encheriam o mundo". Foi assim no passado, é assim no presente. O que pode estar escondido por um muro ou o que impele a construção de muros são elementos que, ao serem analisados, possibilitam uma melhor compreensão do contexto social no qual estamos inseridos. Uma cidade e a educação escolar podem ser compreendidas por meio do estudo dos significados e das representações dispostas nos muros. Sobre essa temática, o presente artigo foi elaborado.

A título de contextualização da pesquisa que gesta as análises a serem apresentadas, recorreu-se a duas situações que auxiliaram a pensar na relação que se estabelece entre os habitantes de uma cidade e os muros e a função da arte na reconceitualização dos muros. A primeira trata-se de uma situação pontual identificada em um bairro periférico da cidade de Londrina, no Estado do Paraná: uma escola municipal que foi construída no final da década de 60 do século 20 para atender alunos da fase escolar, então denominada de primário (primeiro ao quarto ano), por meio de uma parceria entre a Prefeitura e os moradores. A Prefeitura forneceu o material e os moradores a mão de obra.

Quando, nos anos de 2003 e 2004, houve o envolvimento com essa escola para o desenvolvimento de uma pesquisa, ${ }^{4}$ identificou-se que havia um sentimento de pertencimento muito forte entre os moradores do bairro e a escola. Muitos deles, já idosos, paravam em frente à escola e, com orgulho, explicavam aos pais e alunos que participaram da construção dela. O muro existente era composto por uma parte fechada não muito alta - uns 70 centímetros no máximo - e uma parte vazada, característica marcante dos poucos muros ainda existentes na cidade, remanescentes das décadas de 50 e 60, o que permitia que os alunos, ao brincarem no parquinho e embaixo de um belo e imenso flamboyant, olhassem para a rua. Além disso, favorecia que os transeuntes tivessem uma visão do que acontecia na escola. Era comum encontrar pessoas, principalmente idosas, encostadas no muro, acompanhando as atividades das professoras e dos seus alunos. Ocorre que, no ano de 2005, a escola foi transferida para outro prédio, o qual passou a ser usado para abrigar uma escola estadual, atendendo alunos de quinto a oitavo ano.

Uma das primeiras ações da direção da nova escola foi derrubar o muro vazado e construir um muro alto - com mais de dois metros -, o que isolou totalmente a escola da comunidade e a comunidade da escola. É certo que há razões plausíveis para a tomada de tal decisão e não cabe aqui, nos limites do recorte escolhido para este artigo,

OLIVEIRA, Sandra Regina Ferreira de. Educação histórica e a sala de aula: o processo de aprendizagem em alunos das series iniciais do ensino fundamental. 2006. 272 p. Tese (Doutorado) - Universidade Estadual de Campinas, Faculdade de Educação, Campinas, SP. Disponível em: http://www.repositorio.unicamp.br/handle/REPOSIP/252622. 
adentrar em tais especificidades. O que se destaca é que chamou a atenção o quanto aquela mudança arquitetônica causou impacto, principalmente nos moradores do bairro que não aprovaram tal opção. Inferiu-se que a escola, ao ser vista por todos, era também frequentada e assumida por todos. Com o passar do tempo, notou-se que, 14 anos depois, a escola está lá, no mesmo lugar, mas não dialoga na mesma intensidade com o bairro. Teria o muro alto contribuído para tal circunstância?

A segunda situação à qual se recorreu foi amplamente divulgada no mundo e se refere a uma das manifestações artísticas - pois se tem várias - alocadas no muro entre os Estados Unidos e o México: a instalação de gangorras para que crianças dos dois países possam brincar juntas. A ideia foi concebida por Ronald Rael, professor de arquitetura da Universidade da Califórnia, em Berkeley, e por Virginia San Fratello, professora de design da Universidade Estadual de San José, também na Califórnia. A localidade escolhida foi entre o Sunland Park, no Novo México, e Ciudad Juárez, no México ${ }^{5}$. 0 projeto recebeu um nome instigante: Muro Gangorra. A subversão da ideia de muro, transpassado aqui pelo elemento gangorra, possibilitou, conforme as palavras de Rael (em entrevista a Samuel Osborne, em 2019), uma ligação entre as pessoas, crianças e adultos, que "[...] conectaram-se de maneira significativa de ambos os lados, com o reconhecimento de que as ações que acontecem de um lado têm consequência direta do outro lado"6 ${ }^{\text {. }}$

As duas situações relatadas remetem às relações que são desencadeadas entre o externo e o interno a partir das consequências que as ações de ocupação dos muros entrelaçam com a arte urbana. Tem-se o pressuposto de que o estudo de tais relações pode auxiliar na compreensão da relação cidade-escola e, mais especificamente, admitir que o muro da escola pode ser compreendido como um grande painel expositor, em que aquela comunidade externaliza assuntos que entende necessários serem do conhecimento da comunidade externa. Assim sendo, torna-se relevante questionar: $\mathrm{O}$ que os muros externos das escolas revelam? O que os estudantes valorizam nas fachadas das escolas? O que os provoca? Quais são as razões e as motivações que levam algumas escolas a ocuparem seus muros com grafites, desenhos ou outra manifestação de arte urbana? Quais os desdobramentos de tal ação no cotidiano de tais escolas?

Essas e outras perguntas instigaram a ponto de se pesquisar esse espaço de socialização da fachada das escolas; espaço que revela o ambiente escolar. Assim, seguiu-se pesquisando em tese de doutoramento (iniciada em fevereiro de 2019) sobre a arte urbana, simbolizada pelos grafites e pelas pinturas dos muros escolares (escolas públicas e privadas) da cidade de Londrina (PR), procurando entender o papel da cultura, do estudo da cidade, das cidades educadoras, do grafite e da arte mural, além da criatividade, da linguagem e da expressão visual e gráfica, para, então, se localizar o papel que a arte urbana expressa nos muros pintados nas escolas e o que desempenha nas mais

OSBORNE, Samuel. Artistas instalam gangorras em muro entre EUA e México para permitir que crianças brinquem juntas. O Globo, 30 jul. 2019. Atualizado em: 6 ago. 2019. Caderno Mundo. Disponível em: https://oglobo.globo. $\mathrm{com} /$ mundo/artistas-instalam-gangorras-em-muroentre-eua-mexico-para-permitir-que-criancas-brinquemjuntas-23842975. Acesso em: dez. 2019.

6 OSBORNE, Samuel. Artistas instalam gangorras em muro entre EUA e México para permitir que crianças brinquem juntas. O Globo, 30 jul. 2019. Atualizado em: 6 ago. 2019. Caderno Mundo. Disponível em: https://oglobo.globo. com/mundo/artistas-instalam-gangorras-em-muroentre-eua-mexico-para-permitir-que-criancas-brinquemjuntas-23842975. Acesso em: dez. 2019. 
variadas facetas que compõem o cotidiano escolar. Para tanto, foram mapeadas cinco escolas que utilizaram seus muros com o que se denomina arte urbana; avançou-se no sentido de ouvir, por meio de entrevistas junto a alunos, professores, gestores e moradores do bairro, como foi pensada a ideia inicial. Trata-se, então, de uma pesquisa situada entre os campos dos estudos da cidade e dos estudos da instituição escola, ambos interdisciplinares.

Neste texto, em específico, apresentam-se resultados parciais da pesquisa, resultantes da análise dos muros de uma escola pública por meio de registro fotográfico, publicação jornalística e abordagem teórica. São questionados quais os caminhos percorridos para a efetivação da arte urbana, como e quais foram os sujeitos envolvidos e quais são as reverberações dentro do espaço escolar e do bairro. Tece-se a rede de sustentação teórica recorrendo a autores que tratam das temáticas do estudo da cidade, como Silvia Alderoqui (2003), Sandra Pesavento (1995, 2007), Sonia Miranda e Joan Blanch (2014) e Sonia Miranda, Andrea Medeiros e Fabiana Almeida (2016), da linguagem da arte urbana, como Nicholas Ganz (2010), Renato Silva (2009) e Benedito Nunes (2016), da escola, como José Sacristán (2013) e Jaume Bonafé (apud BASILIO, 2014), além da análise das ações ocorridas nas escolas para compreender o envolvimento de gestores, professores, alunos, familiares e comunidade do bairro.

\section{A CIDADE COMO CONTEÚDO PARA A ESCOLA E AS ESCOLAS COMO TERMÔMETRO PARA AS CIDADES}

A pesquisadora argentina Silvia Alderoqui (2003) entende a cidade como um território que educa e, complementando, é educada a partir das devolutivas que recebe das várias instituições que compõem esse território. A escola é uma dessas instituições que, dialeticamente, dialoga com a cidade, com potencialidade de transformá-la e ser transformada por ela. Para que tal relação ocorra, é preciso pensar em um perfil de escola que entenda a cidade como conteúdo importante para compor os currículos a serem desenvolvidos.

Aliando essas colocações aos estudos de Jaume Martínez Bonafé (apud SACRISTÁN, 2013), partiu-se da premissa de que se faz necessário que a cidade seja compreendida como um currículo aberto e gerador de múltiplos recortes que podem indicar conteúdos mais significativos para serem estudados em sala de aula. O pesquisador espanhol propõe assumir os temas e as vivências citadinos não como alavancadores, a fim de que os alunos tenham interesse pela aprendizagem dos conteúdos canônicos que compõem os desenhos curriculares de disciplinas como a Matemática, a Geografia ou a História e todas as demais, mas para compreender a cidade a partir dos movimentos que se articulam e acabam por configurar uma cultura com traços específicos, na qual a escola também se insere.

Assim, a proposta é que a cidade seja entendida como um texto a ser redigido pelos alunos, sempre a partir dos assuntos que, por diferentes razões, fazem-se essenciais para serem pautados como conteúdos a serem ensinados para um certo grupo de alunos em uma determinada escola. Bonafé, em entrevista ao Portal Aprendiz, entende que o texto da cidade, atualmente, é escrito por uma "[...] pedagogia do capitalismo, 
mas há também outras linguagens, outros significados, outras práticas sociais que têm a ver com os movimentos sociais e com um currículo contra-hegemônico". Desse modo, propõe explorar "[...] a ideia da cidade fazendo currículo" (BONAFÉ apud BASILIO, 2014).

Estender as ações da escola para além dos seus muros é um recurso ao qual se recorre, geralmente, como estratégia pedagógica diferenciada, que objetiva iniciar ou finalizar um ciclo de aprendizagem, quer seja um tema ou um ano letivo. Em tal configuração, o que se identifica são realizações de visitas a diversos lugares que - nem sempre - provocam alterações, quer seja na metodologia utilizada pelos professores para ensinar sobre a cidade, quer seja na seleção dos conteúdos a serem ensinados sobre a cidade. A cidade é lida pela escola como um campo para receber visitantes, não na perspectiva almejada por Bonafé (BASILIO, 2014).

Ainda que o perfil descrito sobre a forma como a escola trabalha com as saídas dos alunos para a cidade ainda se mantenha em muitas instituições, é fato que, desde o final do período ditatorial no país, em 1984, têm-se pesquisado e colocado em prática outras formas de apropriação da cidade como conteúdo escolar. As propostas curriculares redigidas pós-ditadura civil militar, progressivamente, indicaram a importância das atividades realizadas em diferentes espaços da cidade. No início do século 21 ampliaram-se significativamente as pesquisas sobre aprendizagem e formação de professores, e concluiu-se que a inserção efetiva de estudos sobre temáticas advindas do entorno é potente mobilizadora para o processo de aprendizagem de professores e alunos.

Os resultados expostos em vasta bibliografia subsidiaram mudanças quanto ao estudo das cidades nas escolas e, também, quanto ao estudo das escolas: não se tratava mais de ensinar aos alunos sobre a cidade, mas de propor investigações para que os estudantes construíssem os seus textos sobre a cidade, e, assim, paralelamente, entendessem-na como um extenso texto que possibilita diferentes leituras e está sempre em processo de elaboração. No mesmo sentido, nas pesquisas sobre as escolas, em seus diversos recortes temáticos, assumiu-se que nenhum aspecto da escola pode ser compreendido de maneira dissociada de seu entorno.

Nas pesquisas que inter-relacionam escola e cidade, esta última passou a ser compreendida como um campo repleto de significados, em que os sujeitos produtores e/ou consumidores dos espaços manifestam seus anseios e imprimem sua marca, de modo que ler a cidade conduz à compreensão das relações que a constituem e da qual se faz parte. Esse fenômeno corresponde à capacidade de perceber e de traduzir a cidade por meio de vivências, memórias, emoções, realizações e posicionamentos, dentre os quais se encontram as manifestações expostas nos muros escolares.

De acordo com Pesavento (2007, p. 14), “[...] a cidade, na sua compreensão, é também sociabilidade: ela comporta atores, relações sociais, personagens, grupos, classes, práticas de interação e de oposição, ritos e festas, comportamentos e hábitos". Para a autora, a cidade compõe-se pelos fragmentos que constituem a história local, retratando e contrastando diferentes grupos, manifestações e temporalidades, apontando elementos de transformação, permanência e mudança. Desse modo, tempo e espaço se entrecruzam no contexto da cidade e de suas relações, constituindo-se num cenário constantemente renovável, capaz de oportunizar novos olhares e aprendizagens àque- 
les que se dispõem a "[...] ver um pouco mais além, talvez, do que já foi visto, despertando para o presente as múltiplas cidades do passado que as de hoje encerram" (PESAVENTO, 1995, p. 16).

Para tanto, é preciso percorrer seus caminhos físicos e imaginários, observando materialidades, possibilidades, imagens e discursos que da cidade emanam, além de atentar para a diversidade de vozes e sujeitos que se encontram e oportunizam saberes, conhecimentos e narrativas históricas. Nesse curioso processo de superposição de tramas e enredos, as narrativas são dinâmicas e desfazem a suposta imobilidade dos fatos. Personagens e acontecimentos são sucessivamente reavaliados para ceder espaços a novas interpretações e configurações, dando voz e visibilidade a atores e lugares (PESAVENTO, 2007, p. 17).

No mais, as visões e os entendimentos sobre passado, presente e futuro da cidade manifestam-se por meio de planejamentos urbanos, discursos de modernidade e processos de revitalização e de preservação dos espaços, confrontando a cidade idealizada e a cidade real, bem como as intenções que se materializam na paisagem e no modo de vida das pessoas no local que se dá a reescrever.

Com base nesses elementos, o estudo das representações constantes nos muros das escolas é um caminho para a cidade adentrar o currículo e os espaços escolares, construindo e desconstruindo narrativas urbanas. A pesquisa, nessa perspectiva, potencializa a cidade como espaço educador e de múltiplas aprendizagens.

Ao refletirem sobre as potencialidades educativas da cidade, Miranda e Blanch (2014) e Miranda, Medeiros e Almeida (2016) veem nela inúmeras possibilidades para o trabalho de formação da consciência histórica. Para os autores, a educação, com, na e pela cidade, oportuniza a consciência sobre o tempo presente, favorecendo a existência de uma consciência sobre o passado, além de criar condições de reflexão acerca de projetos para o futuro. Nesse âmbito, a cidade apresenta-se como espaço privilegiado para se pensar sobre as complexidades temporais e os sentidos que agregam, otimizando olhares, indagações, investigações e compreensões a partir do urbano e de suas contemplações.

Ao analisar as expressões presentes nos muros das escolas que ocupam esse espaço de forma planejada e intencional, é possível compreender quais as mensagens que a escola pretende divulgar junto a comunidade e, em certa medida, inferir sobre as respostas esperadas. O muro é, então, uma janela pela qual se externalizam ações no intuito de publicizar assuntos que são considerados importantes ou divulgar trabalhos cujos resultados foram entendidos pela comunidade escolar como significativos para serem conhecidos pelos transeuntes. A arte, portanto, é uma linguagem poderosa no estabelecimento de tal comunicação.

\section{A LINGUAGEM DA ARTE URBANA}

Não há como determinar exatamente como e quando se iniciou o grafite. Existem várias teorias, desde as figuras encontradas nas Grutas de Lascaux, na França, que eram gravadas com ossos e pedras. Muitos movimentos usaram o grafite, como o nazismo e 
as revoltas estudantis, mas "[...] o grafite começou a se desenvolver na década de 1970, em New York e na Filadélfia, onde artistas [...] pintavam seus nomes nos muros ou nas estações de metrô ao redor de Manhattan" (GANZ, 2010, p. 8).

As técnicas também evoluíram. Além do uso das latas de spray, muitos grafiteiros exploram outros materiais, como stickers (etiquetas), pôsteres, estênceis, aerógrafos, pastéis oleosos, tinta a óleo ou acrílica, todas as variedades de tinta e até mesmo esculturas. Muitos chamam o grafite de arte de rua ou de arte urbana, e essa arte, que teve início com letras grafitadas nos muros ou tags (assinatura do grafiteiro), expandiu para símbolos, personagens, caricaturas, abstrações, representações do cotidiano, crítica social, fotorrealismo, desenhos cômicos, logotipos, ícones e propagandas. Atualmente, o grafite ganhou espaço nos museus mais famosos do mundo, arrastando milhares de jovens sob seu fascínio.

Com o hip-hop, o punk e a internet, o grafite foi introduzido em quase todos os países ocidentais e também nos países orientais influenciados pelo Ocidente, alcançando em seguida lugares ainda mais distantes. Embora só mais tarde tenha chegado à Ásia e à América do Sul, hoje a cultura do grafite nesses lugares cresce a uma velocidade surpreendente, tendo já alcançado um alto padrão, principalmente na América do Sul (GANZ, 2010, p. 9).

No Brasil, os grafiteiros mais conhecidos internacionalmente são Os Gêmeos, de São Paulo. Iniciaram em 1986 e abriram caminho para a arte urbana brasileira. "Ganharam reconhecimento por seus personagens, feitos com frequência usando um estilo distorcido, típico das histórias em quadrinhos. Os Gêmeos são improvisadores, suas obras tendem a refletir suas personalidades, experiências e emoções (GANZ, 2010, p. 85).

As grafitagens compõem a paisagem urbana e não mais carregam a acusação de vandalismo, que compartilhavam com os pichadores.

[...] as imagens desenhadas e pintadas nos muros resultaram no grafite, linguagem visual gerada nas ruas, alimentada por referências de tradição popular e dos meios de comunicação, das informações da história da arte e das soluções encontradas pelo autodidata, do universo erudito e da cultura pop. A linguagem do grafite é constituída pela contribuição de cada autor (anônimo ou nomeado) e peculiar a cada cidade. É inconfundível e não se adultera mesmo quando deslocada de seu nascedouro (SILVA, 2009).

O grafiteiro vai para a rua pintar sobre superfícies que não lhe pertencem, sejam muros de casas e empenas de edifícios ou locais de trânsito público, como túneis e viadutos. Conforme afirma Silva (2009), "O grafiteiro não pede licença, arrisca-se".

A linguagem do grafite, da arte urbana, é considerada uma linguagem visual, pois abarca símbolos, ícones, caricaturas, representações da realidade e do contexto social, que, por ser uma arte de rua, pode ser desfeita e refeita rapidamente. A arte urbana, aliada à educação, potencializa o papel estético, impulsiona a imaginação e amplia seu efeito formador.

A imagem não somente cristaliza uma dada realidade social, mas responde ativamente às solicitações de seu meio, às exigências de sua classe, aos problemas morais, sociais e políticos de sua época. "Sua resposta importa num desvendamento ou numa 
constatação, numa descoberta ou numa recusa, sem excluir a própria aceitação daquilo que existe e que, no entanto, recebe, na obra, uma expressão reveladora e ampla dirigida a todas as consciências" (NUNES, 2016, p. 98).

\section{EXPERIÊNCIAS MURAIS ESCOLARES}

"[...] jamais se deve confundir uma cidade com o discurso que a descreve. Contudo, existe uma ligação entre eles" (CALVINO, 2017, p. 59). Citando o pensamento de Italo Calvino sobre as cidades, pode-se ampliar essa ideia para o campo dos muros escolares sem confundir a pintura dos muros externos com o movimento interno da escola, as disciplinas, os projetos e afins, mas não se pode negar a relação entre a arte urbana expressa na pintura ou no grafite que os alunos almejam ter na escola.

Os muros das escolas expressam um rico material e fonte de pesquisa, pois são constituídos de imagens que revelam sobre o contexto social, simbólico e representativo do universo desses jovens. A arte urbana presente nos muros escolares é uma arte comprometida com as realidades social, política, ideológica, entre outros temas relevantes. Ademais, revela um universo lúdico, de sociabilidade e pertencimento.

Para efetuar a análise da escola, pontua-se um caso relevante de uma escola pública da cidade de Londrina (PR) - a qual optou por trabalhar a arte urbana em seus muros -, procurando explicitar, por meio da pesquisa exploratória descritiva com base na reportagem jornalística "Passeio pela leitura nos muros da escola", de Ogawa (2018), como ocorreu a ação e seus desdobramentos. Todos os dados foram coletados com reportagem jornalística e registro fotográfico.

Essa escola estadual foi fundada em 1998. Possui, atualmente, 593 alunos que frequentam o ensino regular nos períodos da manhã e da tarde e, no período noturno, a Educação de Jovens e Adultos (EJA), com 45 professores nos três períodos. A motivação para a grafitagem e para a pintura dos muros da escola foi o vandalismo existente. Segundo a diretora, "os muros eram muito depredados, com palavrões e figuras feias. A gente sabia que, se pintássemos o muro normalmente, os pichadores voltariam e estragariam tudo novamente". Assim, surgiu o projeto de grafite em 2018.

Um ex-aluno grafitou um pedaço do muro na entrada da escola e onde ele fez a arte ninguém mais pichou. Então, a diretora percebeu o interesse dos alunos pelo grafite e a motivação que trouxe para a escola. Dispôs-se a retratar nos muros o projeto que mais bem funcionava na escola. "Decidimos retratar lá fora o que vivemos aqui dentro e uma das coisas mais fortes é o projeto da leitura, que funciona muito bem, porque nossa bibliotecária é uma pessoa muito ativa", declarou a diretora.

A bibliotecária indicou quais livros eram mais procurados entre os alunos e as obras clássicas que precisavam constar nos muros. Foram realizados grafites e pinturas, respectivamente. Na entrada da escola, os livros foram pintados como se estivessem em uma estante da biblioteca, ilustrando a lombada com o título da obra; alguns, com a capa planificada (Figura 1). 
Figura 1 - Pintura da lombada dos livros da biblioteca no muro de entrada da escola

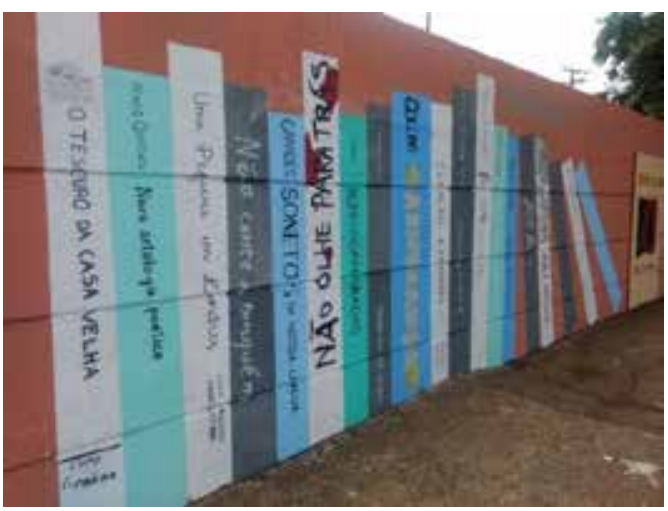

Fonte: As autoras, fev. 2019.

A imagem emociona. Ao verem arte na rua as pessoas param, recordam, memoriam. Algumas imagens destacam-se pela forte emoção que expressam, pela agressividade ou pela repulsa; a arte urbana revela a habilidade do artista de despertar a emoção de quem está passando pela rua. Normalmente esse tipo de arte extrapola o tamanho do habitual; é tão grande que é impossível não ver; pode ocupar empenas inteiras de prédios ou muros, e estes estão presentes em todas as cidades, guardando e protegendo, mas também revelando por meio da arte.

[...] o artístico desperta necessariamente no público uma emoção especial, de encantamento e enlevo ou até mesmo de medo, que pode ser identificado como prazer estético, pois surge da contemplação e da fruição da obra, de suas qualidades formais e de linguagem. Essa emoção difere daquela que temos cotidianamente diante dos fatos da vida, porque sabemos que ela é fruto da imaginação do autor e da nossa também, que é capaz de entendê-la. Assim, tanto o prazer que sentimos diante de uma paisagem agradável como a sensação de suspense que temos ao ver alguns filmes resultam do domínio do autor sobre a arte com a qual se expressa, das qualidades estéticas de sua obra (COSTA, 2001, p. 19-20).

Figura 2 - Grafite realizado por um ex-aluno da Escola. Capa do livro "Dom Casmurro", de Machado de Assis

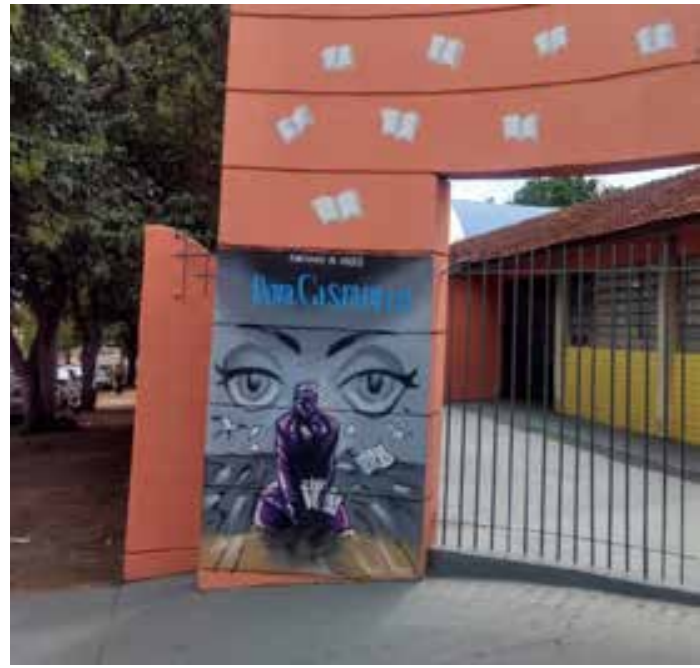

Fonte: As autoras, fev. 2019. 
Além de ser capaz de explicar e de esclarecer, a arte, por meio das imagens, pinturas e grafites, tem o poder de complementar, transmitir uma informação e aprofundar sobre o tema de que se está tratando. Pode, ainda, aprofundar um conteúdo ou revelar aspectos artísticos, como encontra-se nos traços dos grafiteiros famosos, reconhecidos em todo o mundo.

A fonte da criatividade artística, assim como de qualquer experiência criativa, é o próprio viver. Todos os conteúdos expressivos na arte, quer sejam de obras figurativas ou abstratas, são conteúdos essencialmente vivenciais e existenciais. Também os acasos podem ser caracterizados como momentos de elevada intensidade existencial, porquanto a criatividade é estreitamente vinculada à sensibilidade do ser. Ambas se complementam, sendo impensáveis uma sem a outra (OSTROWER, 1999, p. 7).

Em outros espaços dos muros foram grafitados e pintados temas sociais trabalhados na escola, como inclusão, preconceito, indígenas, brasilidade, paz, leitura, cidadania, educação, respeito, etnias, fantasia, entre outros permitidos pela criatividade dos alunos.

É importante destacar que a escola escolheu o grafite, apesar de saber se tratar de material caro para sua aquisição e da necessidade de mais treino e técnica para a execução das figuras pelos próprios alunos ou mesmo por profissionais.

As relações colaborativas em atividades coletivas, focalizando conflitos, buscam compreender e explicar as ações dos sujeitos voltadas à criação de possibilidades de transformação dos contextos em que atuam. Ao tratar dos conceitos e das práticas educacionais, como o relato da experiência vivenciada pelo colégio entre equipe pedagógica e alunos, "toda atividade de trabalho organiza-se em torno de um objeto, considerado o real motivo da atividade" (ENGESTROM, 1987 apud NININ; MAGALHÃES, 2017, p. 628).

Sendo assim, de acordo com a teoria sócio-histórico-cultural, a participação da funcionária da escola, em conjunto com a direção, foi fundamental para a evolução e para a transformação da biblioteca em algo maior, que despertasse interesse e procura dos alunos, gerando curiosidade e mais apreço pelos livros.

A escola, por sua vez, desenvolveu a capacidade dos sujeitos para, conscientemente, ampliar e alterar suas atividades profissionais a fim de conseguir discutir questões complexas com a comunidade, nesse caso, com os alunos e seus familiares, a partir das manifestações das contradições, ou seja, dos conflitos e dilemas vivenciados pelos sujeitos, como a pichação e o vandalismo nos muros da escola praticados por pessoas que não respeitam esse espaço de pertencimento dos alunos.

\section{AMBIENTE TRANSFORMADOR}

O muro torna-se a identidade do lugar, um cartão de visitas, um convite a entrar e a conhecer. Faz parte de espaços coletivos que surgiram e desapareceram, mas que contribuíram para a valorização da cena da arte urbana. A arte urbana existe e resiste ao passar do tempo, mesmo em movimentos cíclicos, contudo com potencial de intervenção cada vez maior. Os muros são os suportes favoritos para se usar os sprays multi- 
coloridos e ressignificar os lugares; são símbolo da sociedade moderna e, não por acaso, também suporte favorito dos grafiteiros. O objetivo, também, é quebrar preconceitos e aproximar a sociedade em geral, longe de publicidade e propaganda, distante de imagens que induzem ao consumo. O grafite pode, mesmo que por um momento breve, arrancar-nos desse modo automático a que estamos submetidos no dia a dia.

A leitura enriquece as ideias e as experiências intelectuais, no entanto os alunos da escola em questão não tinham um espaço apropriado, porque a biblioteca havia sido incendiada de maneira criminosa em 2012. A equipe escolar, então, juntamente com a diretoria, limpou uma sala de aula, fez calçada, colocou sofá, ar condicionado e criou um ambiente prazeroso para os alunos.

Muitos alunos gostaram bastante da nova pintura. Alguns, que não tinham lido as obras pintadas nos muros, procuravam na biblioteca; outros não conheciam as obras e tomaram conhecimento depois das pinturas. Estas provocaram a curiosidade e estimularam a leitura das obras.

Os pais dos estudantes também modificaram sua visão da escola, elogiando a inspiração para a leitura e procurando vagas na escola que demostra, por meio dos muros, tanto zelo. A vizinhança também aprovou a iniciativa, relatando a sensação de limpeza e beleza, além da curiosidade e do retorno ao passado das leituras já feitas - ou não - na época escolar.

A ação educativa - evidenciada a partir de suas práticas - permite aos alunos avançar em saltos na aprendizagem e no desenvolvimento. É a ação sobre o que o adulto consegue fazer, com a ajuda do outro para que consiga fazê-lo sozinho. Entretanto, é princípio de toda instituição de ensino (principalmente da escola) garantir a aprendizagem a todos, visto que todos são capazes de aprender (LEITE; LEITE; PRANDI, 2009, p. 204).

A ação educativa, o conhecimento e a aprendizagem são etapas fundamentais no processo pelo qual nos tornamos quem somos. Trata-se de uma relação complexa entre o individual e o coletivo, que envolve a participação ativa na transformação de si, do outro e do mundo, criando a possibilidade de falar, aprofundar, questionar, esclarecer e explicitar ideias e compreensões sobre a leitura e sobre outros temas grafitados e pintados nos muros da escola.

Apesar de ser apenas uma narrativa da arte urbana ocorrida na escola, a observação propôs a leitura da participação da direção, da bibliotecária, dos professores e dos alunos das escolas, buscando avançar na compreensão e na transformação de seus contextos de ação, aprimorando a leitura, envolvendo os vizinhos, os familiares e discutindo preconceitos dentro e fora dos muros escolares.

\section{CONSIDERAÇÕES FINAIS}

Hoje vive-se na chamada "civilização da imagem", na era da visualidade, da cultura visual; há imagens por toda parte. Com essa produção maciça, tendo como exemplo a arte urbana, modificaram-se as bases do conhecimento humano. A arte urbana muda 0 ritmo de quem passa; os passos apressados param quando se deparam com uma visão interessante que pode ser admirada ou fazer pensar, refletir. Olha-se com novo olhar para o lugar de sempre. 
Desse modo, a arte lança outra perspectiva para um lugar onde nem se reparava mais. Interrompe a rotina e faz reparar, e apreciação não é, necessariamente, aprovação; pode-se estranhar, achar diferente. Os sujeitos passam a ler e a tentar interpretar a mensagem descrita pela pintura ou pelo grafite, a relação com seu cotidiano, a beleza e o colorido que enobrece. Os muros transformam-se em verdadeiras telas urbanas.

A arte urbana e a escola formam uma complementaridade possível e desejável entre as formas de discurso. Sendo assim, pode-se comprovar que a arte urbana construiu um novo conceito de muro para a escola, pois, a partir de um problema, os gestores e os alunos agruparam-se e utilizaram a arte urbana como fonte de resolução, gerando participação e envolvimento dos alunos, da equipe gestora e dos familiares, além da vizinhança, a qual se identificou com o projeto da escola, relembrando obras lidas ou conhecidas no passado e fazendo referência a conteúdos que fazem parte de sua vida.

A abundância de novas possibilidades de exploração da arte urbana na escola pede novas estratégias, novos conteúdos, novas formas de contextualização, de participação. Aprende-se a criar, a usar a criatividade para extrapolar os limites que a sala de aula impõe para educar o olhar, a ser mais sensível em relação ao presente vivido, a observar a condição e estabelecer relações.

A arte urbana torna-se, então, parte significativa da vida urbana. A arte contemporânea pública propõe-se a ser uma força constitutiva no modo de construção das interações sociais. Considera-se, aqui, que a cidade e a educação escolar podem ser compreendidas por meio do estudo dos significados e das representações dispostos nos muros. Nesse contexto, esta pesquisa intentou olhar para a escola a partir de um viés diferente e com tentativas de estabelecer conexões possíveis entre a cidade e a escola.

Tais projetos e etapas do desenvolvimento desempenham uma proposta diferente para cada escola, para cada cidade, articulando as disciplinas, os gestores das escolas, os professores, os alunos e a comunidade. Todos unem-se para que a escola se torne $o$ centro do processo de ensino-aprendizagem, articulando escola e cidade e buscando, pelas representações visuais dos muros, aprender sobre os mais diversos temas explorados, enfrentando os problemas com criatividade.

Dessa maneira, cidade-escola-arte complementam-se, interagindo e proporcionando a todos diversidade cultural, pensando em novas alternativas para enfrentar os percalços criativa e ativamente. Extrapolando os limites dos muros, a escola revela conteúdos sociais, políticos, econômicos, raciais, entre outros temas polêmicos, fazendo com que a sociedade reflita conteúdos de sala de aula, possibilitando a participação ativa ao provocar questões e esclarecer ideias.

\section{REFERÊNCIAS}

ALDEROQUI, Silvia. La ciudad um território que educa. Caderno CRH, Salvador, n. 38, p. 153-176, jan./jun. 2003.

BASILIO, Ana Luiza. A cidade como currículo: pesquisador espanhol desafia escola a olhar a rua. Portal Aprendiz, 12 nov. 2014. Disponível em: https://portal.aprendiz.uol.com.br/2014/11/12/cidade-como-curriculo-pesquisador-espanhol-desafia-escola-olhar-rua/. Acesso em: dez. 2019.

CALVINO, Italo. As cidades invisíveis. São Paulo: Companhia das Letras, 2017.

COSTA, Cristina. Questões de arte: a natureza do belo, da percepção e do prazer estético. São Paulo: Ed. Moderna, 2001. 
GANZ, Nicholas. O mundo do grafite: arte urbana dos cinco continentes. São Paulo: Livraria Martins Fontes Editora, 2010.

LEITE, Carla A. R.; LEITE, Elaine C. R.; PRANDI, Luiz P. A aprendizagem na concepção histórico cultural. Akrópoli, Umuarama, v. 17, n. 4, p. 203-210, out./dez. 2009.

LORCA, Federico García. Obras completas de Federico García Lorca. Iberial Literatura Copyright, 2015. Disponível em: http://www.dominiopublico.gov.br/pesquisa/PesquisaObraForm.do?select_action=\&co_autor $=1960$.

MEDEIROS, Maria Beatriz (org.). Arte em pesquisa: especificidades. V. I. In: ENCONTRO NACIONAL DA ANPAP, 13., 2004. Brasília. Anais [...]. Brasília: Anpap; Editora do PPGA/UnB, 2004.

MIRANDA, Sonia R.; BLANCH, Joan P. Miradas sobre uma questão sensível: a cidade em suas potencialidades educativas. In: ENCONTRO NACIONAL PERSPECTIVAS DO ENSINO DE HISTÓRIA, 8., 2012. Campinas. Anais [...]. Campinas: Unicamp, 2012. p. 1-30.

MIRANDA, Sonia. R.; MEDEIROS, Andrea B.; ALMEIDA, Fabiana R. A cidade para professores. Juiz de Fora, Minas Gerais: Funalfa, 2016.

NININ, Maria Otilia G.; MAGALHÃES, Maria Cecilia C. A linguagem da colaboração crítica no desenvolvimento da agência de professores de ensino médio em serviço. Alfa, São Paulo, v. 61, n. 3, p. 625-652, 2017.

NUNES, Benedito. Introdução à filosofia da arte. São Paulo: Edições Loyola, 2016.

OGAWA, Vitor. Passeio pela leitura nos muros da escola. Folha de Londrina, Londrina, 27 dez. 2018. Caderno Cidades. Disponível em: https://www.folhadelondrina.com.br/cidades/passeio-pela-leitura-nos-muros-da-escola-1023229.html. Acesso em: jan. 2019.

OSTROWER, Fayga. Acasos e criação artística. Rio de Janeiro: Elsevier, 1999.

PESAVENTO, Sandra Jatahy. Cidades visíveis, cidades sensíveis, cidades imaginárias. Revista Brasileira de História, São Paulo, v. 27, n. 53, 2007. Disponível em: http://www.scielo.br/scielo.php?script=sci_arttext\&pid=S0102-01882007000100002. Acesso em: jan. 2020.

PESAVENTO, Sandra Jatahy. Muito além do espaço: por uma história cultural do urbano. Estudos Históricos, Rio de Janeiro, v. 8, n. 16, 1995. Disponível em: bibliotecadigital.fgv.br/ojs/index.php/reh/article/ download/2008/1147. Acesso em: jan. 2020.

SACRISTÁN, José G. (org.). Saberes e incertezas sobre o currículo. Porto Alegre: Ed. Penso, 2013.

SANTOS, Boaventura de Sousa. Reconhecer para libertar. São Paulo: Ed. Civilização Brasileira, 2003.

SILVA, Renato. Os gêmeos. São Paulo: FAAP, 2009. 